\title{
Ericaceae da Serra Negra, Minas Gerais, Brasil
}

\author{
Ericaceae of the Serra Negra, Minas Gerais, Brazil
}

Andressa Cabral ${ }^{1,4}$, Gerson O. Romão ${ }^{2}$, Sabrina A. $\operatorname{Roman}^{1}$ \& Luiz Menini Neto ${ }^{3}$

\begin{abstract}
Resumo
A Serra Negra é um fragmento do Complexo da Mantiqueira, localizado entre os municípios de Lima Duarte, Santa Bárbara do Monte Verde, Rio Preto e Olaria, com altitudes variando entre 800 e $1700 \mathrm{~m}$. A vegetação apresenta um mosaico composto por florestas e ambientes campestres, destacando-se o campo rupestre por toda a amplitude altimétrica. Um amplo estudo florístico foi realizado entre os anos de 2003 e 2014, e os espécimes coletados foram depositados no Herbário Leopoldo Krieger (CESJ), da Universidade Federal de Juiz de Fora. O objetivo do presente estudo foi realizar um inventário florístico e taxonômico para a família Ericaceae da Serra Negra. Foram registradas oito espécies pertencentes a três gêneros, sendo Agarista e Gaylussacia os mais ricos, com quatro e três espécies respectivamente, e Gaultheria representado por apenas uma espécie. São apresentadas chaves de identificação, descrições das espécies, ilustrações de caracteres diagnósticos e comentários de distribuição geográfica, ecológicos e taxonômicos.
\end{abstract}

Palavras-chave: Complexo da Mantiqueira, Floresta Atlântica, campo rupestre, flora.

\begin{abstract}
Serra Negra is a fragment of the Mantiqueira Range located among Lima Duarte, Santa Bárbara do Monte Verde, Rio Preto and Olaria, with altitudes between 800 and $1700 \mathrm{~m}$. The vegetation is represented by a mosaic of forests and field environments, of which the "campo rupestre" must be highlighted, due to its occurrence in the whole altitudinal range in the area. A wide floristic study was conducted between the years 2003 and 2014 and the collected specimens were deposited in the Herbarium Leopoldo Krieger (CESJ), of the Universidade Federal de Juiz de Fora. The aim of the present study was to conduct a floristic and taxonomic inventory to the family Ericaceae of the Serra Negra. It were recorded eight species belonging to three genera, of which Gaylussacia and Agarista were the richest, with four and three species, respectively, and Gaultheria represented by just one species. Identification keys, descriptions, illustrations of diagnostic characters, and comments of geographic distribution, ecological and taxonomic are provided.
\end{abstract}

Key words: Mantiqueira Range, Atlantic Forest, "campo rupestre”, flora.

\section{Introdução}

Ericaceae apresenta distribuição cosmopolita, ocorrendo principalmente nas regiões temperadas e subtropicais, abrangendo cerca de 4.100 espécies pertencentes a 124 gêneros (Judd et al. 2008). É constituída por plantas geralmente lenhosas, predominantemente arvoretas heliófilas, que preferem habitat de $\mathrm{pH}$ ácido. Muitas espécies são consideradas boas colonizadoras, podendo ser encontradas sob a forma epifítica e epilítica (Stevens 1971). No Brasil, a família é representada por 12 gêneros e 98 espécies, com distribuição predominante nos campos rupestres e de altitude das regiões Sudeste e Sul do país (Souza \& Lorenzi 2012; BFG 2015).

A Floresta Atlântica, um dos hotspots mundiais de biodiversidade, possui um grande número de espécies endêmicas e vem sofrendo

\footnotetext{
${ }^{1}$ Universidade Federal de Juiz de Fora, Inst. Ciências Biológicas, Martelos, 36036-900, Juiz de Fora, MG, Brasil.

${ }^{2}$ Universidade de São Paulo, Escola Superior de Agricultura Luiz de Queiroz, Av. Pádua Dias 11, Agronomia Piracicaba, SP, Brasil.

${ }^{3}$ Centro de Ensino Superior de Juiz de Fora, R. Luz Interior 345, Estrela Sul, 36030-776, Juiz de Fora, MG, Brasil.

${ }^{4}$ Autora para correspondência: acabral@outlook.com.br
} 
rápida redução de sua extensão ao longo dos anos (Myers et al. 2000). Embora o Domínio Atlântico apresente fitofisionomia majoritariamente florestal, a presença de ecossistemas associados (como as restingas e ambientes campestres) permite uma riqueza considerável de espécies de Ericaceae. Com isso, a riqueza de espécies de Ericaceae atualmente registrada para o Brasil, especialmente na Floresta Atlântica, pode estar subestimada. A literatura especializada compreende um amplo estudo sobre Ericaceae no Brasil (KinoshitaGouvêa 1980), revisão taxonômica de Gaylussacia (Romão 2011), além de algumas floras estaduais e ou regionais neste domínio fitogeográfico (e.g., Romão \& Souza 2003; Silva \& Cervi 2006; Marinero et al. 2007; Kinoshita \& Romão 2012; Mezabarba et al. 2013).

Deste modo, o presente estudo vem contribuir com o conhecimento da família Ericaceae no estado de Minas Gerais e tem como objetivos inventariar as espécies ocorrentes na Serra Negra, no Complexo da Mantiqueira, localizado na região sudeste de Minas Gerais, bem como fornecer dados sobre habitats de ocorrência, descrições das espécies, ilustrações e chaves para sua identificação, além de comentários de distribuição geográfica, ecológicos e taxonômicos.

\section{Material e Métodos}

A Serra Negra faz parte do Complexo da Mantiqueira, com limite Norte $21^{\circ} 58^{\prime} \mathrm{S}, 43^{\circ} 53^{\prime} \mathrm{W}$; Sul $22^{\circ} 01^{\prime} \mathrm{S}, 43^{\circ} 52^{\prime} \mathrm{W}$, Leste $21^{\circ} 58^{\prime} \mathrm{S}, 43^{\circ} 50^{\prime} \mathrm{W}$ e Oeste $21^{\circ} 58^{\prime} \mathrm{S}, 43^{\circ} 56^{\prime} \mathrm{W}$, compreendida entre os municípios de Lima Duarte, Santa Bárbara do Monte Verde, Rio Preto e Olaria (Fig. 1). Apresenta altitudes entre 800 e 1700 m.s.m. O clima é do tipo Cwb (Köppen), mesotérmico úmido, com invernos secos e frios e verões brandos e úmidos, apresentando uma precipitação média anual de 1886 mm (Salimena et al. 2013).

A vegetação está inserida no Domínio Atlântico, apresentando um mosaico composto por matas ciliares, campos rupestres, florestas ombrófilas e semidecíduas. Destas, a mais comum é o campo rupestre que está distribuído por toda a amplitude altimétrica, estando representada pelo estrato arbustivo denso nas áreas mais baixas e com um predomínio de espécies herbáceas, distribuídas em afloramentos rochosos, nas cotas mais altas (Menini Neto et al. 2009; Valente et al. 2011; Salimena et al. 2013).

O inventário florístico foi realizado através de cerca de 50 expedições entre os anos de 2003

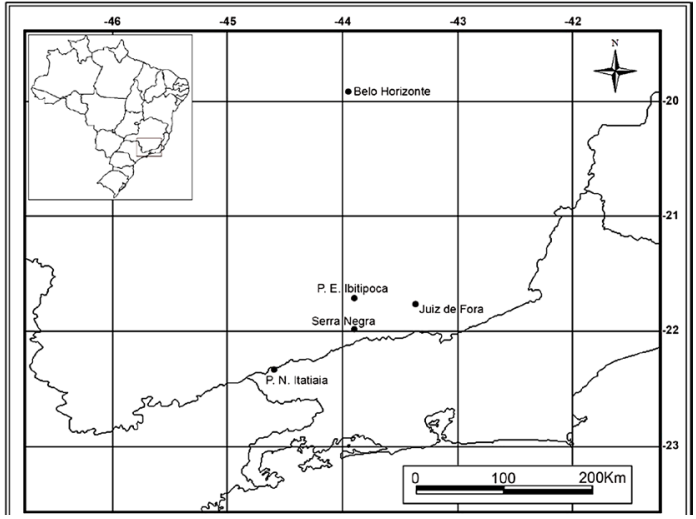

Figura 1 - Localização da Serra Negra, Minas Gerais, Brasil (Fonte: Salimena et al. 2013). Figure 1 - Location of Serra Negra, Minas Gerais, Brazil (Source: Salimena et al. 2013).

e 2014, buscando cobrir a maior parte possível da área estudada. Os espécimes férteis foram coletados, fotografados e herborizados segundo metodologia de Fidalgo \& Bononi (1984), tendo suas principais características anotadas e depositadas posteriormente no Herbário Leopoldo Krieger (CESJ), da Universidade Federal de Juiz de Fora, com duplicatas enviadas para o herbário ESA (acrônimos segundo Thiers, continuamente atualizado). O material examinado está listado em ordem alfabética de município e localidades específicas. No caso de haver mais de um material nestas condições a ordem adotada foi cronológica.

A identificação das espécies e obtenção dos dados de distribuição geográfica foram feitos através de comparação com material já identificado por especialistas, além de consultas a literatura especializada (Kinoshita-Gouvêa 1980; Judd 1995; Romão \& Souza 2003; Romão et al. 2004; Silva \& Cervi 2006; Marinero et al. 2007; Kinoshita \& Romão 2011, 2012; Romão 2011; Mezabarba et al. 2013). As descrições dos gêneros foram baseadas nos espécimes coletados na Serra Negra, e a terminologia morfológica utilizada nas descrições das espécies foi baseada em Radford (1974), Harris \& Harris (2003) e Gonçalves \& Lorenzi (2007).

\section{Resultados e Discussão}

Foram registradas na Serra Negra oito espécies de Ericaceae distribuídas em três gêneros, sendo Agarista e Gaylussacia aqueles com maior riqueza, apresentando quatro e três espécies respectivamente, e Gaultheria representado por apenas uma espécie. Alguns 
Tabela 1 - Comparação entre estudos sobre a família Ericaceae realizados em Minas Gerais.

Table 1 - Comparison between studies about the family Ericaceae conducted in Minas Gerais.

\begin{tabular}{lcll}
\hline Áreas & $\mathbf{N}^{\mathbf{0}}$ de espécies & Referências \\
\hline Serra Negra, MG & 8 & Cabral et al. (neste artigo) \\
Parque Nacional do Caparaó, MG/ES & 6 & Romão \& Souza (2003) \\
Grão-Mogol, MG & 5 & Romão et al. (2004) \\
Parque Nacional do Itatiaia, MG/RJ & 14 & Mezabarba et al. (2013) \\
Parque Estadual da Serra do Papagaio, MG & 10 & Cabral et al. (dados não publicados) \\
\hline
\end{tabular}

estudos florísticos específicos sobre a família realizados em Minas Gerais apresentaram número de espécies semelhante ao do presente trabalho (Tab. 1).

Agarista hispidula (DC.) Hook. ex Nied. e A. oleifolia (Cham.) G. Don var. oleifolia são encontradas na Serra Negra exclusivamente até 1.500 m.s.m. As demais espécies distribuem-se de modo mais uniforme ao longo de toda a amplitude altitudinal da área estudada (entre 800 e 1700 m.s.m.), preferencialmente no campo rupestre. No presente trabalho, os limites da distribuição geográfica de Gaylussacia montana (Pohl) Sleumer var. angustifolia foram ampliados para o Complexo da Mantiqueira, sendo anteriormente considerada endêmica da Cadeia do Espinhaço (Romão 2011).

\section{Chave para identificação dos gêneros de Ericaceae ocorrentes na Serra Negra}

1. Ovário ínfero; fruto do tipo nuculânio Gaylussacia

1'. Ovário súpero; fruto do tipo cápsula.

2. Filetes geniculados; anteras sem aristas ou túbulos terminais Agarista

2'. Filetes não geniculados; antera com aristas ou túbulos terminais Gaultheria

Agarista G. Don ex G. Don

Arbustos a arvoretas, geralmente eretos; ramos glabros a pilosos. Folhas alternas a subopostas, esparsas ou adensadas, coriáceas, margem plana a fortemente revoluta, inteira a ligeiramente ondulada, glabras ou pilosas, geralmente com tricomas glandularescapitados na face abaxial, ápice frequentemente com glândula espessa. Inflorescência tipo panícula ou racemo, axilar a terminal, bracteada na base da raque, glabra ou pilosa; bráctea floral 1; bractéolas 2. Flores pentâmeras actinomorfas, geralmente pendentes; cálice 5-lobado, persistente; corola gamopétala, pentâmera, urceolada ou cilíndrica, alvo-esverdeada, alva, rosada a avermelhada; estames 10, iguais entre si; filete geniculado, achatado, dorso piloso, anteras ovoide-oblongas, bífidas, dorsifixas na metade inferior, deiscência poricida, teca truncada, desprovida de apêndice; ovário súpero, 5-locular, lóculo multiovulado, globoso, estilete filiforme levemente dilatado próximo ao ápice do ovário. Cápsula loculicida, subglobosa com suturas levemente espessadas próximo ao ápice; sementes numerosas, fusiformes.

Agarista abrange 31 espécies, ocorrendo predominantemente nas Américas, com apenas uma espécie na África, A. salicifolia (Lam.) G. Don. No Brasil, estão relacionadas 21 espécies com distribuição predominante nos campos rupestres da Cadeia do Espinhaço até os campos de altitude nas regiões Sul e Sudeste do país (Judd 1995; BFG 2015).

\section{Chave para identificação das espécies de Agarista}

1. Folhas 2-8,4 cm compr., margem plana; pecíolo 5-30 mm compr.

2. Pecíolo 10-30 mm compr., flexível; ramos, raque da inflorescência e pedicelo glabros 
2'. Pecíolo 5-11 mm compr., rígido; ramos esparsamente cano-pubescentes, raque da inflorescência e pedicelo esparsa a densamente cano-tomentosos. 4. A. oleifolia var. oleifolia

1'. Folhas 0,6-1,7 cm compr., margem ligeira a fortemente revoluta; pecíolo 2-4 mm compr.

3. Ramos glabros; folhas glabras a esparsamente cano-pubescentes na nervura principal em ambas as faces; corola alva, glabra 1. A. chlorantha

3'. Ramos esparsa a densamente cano-tomentosos; folhas glabras a esparsamente cano-pubescentes em todo o limbo da face abaxial; corola rósea a avermelhada, esparsa a densamente cano-pubescente 3. A. hispidula

1. Agarista chlorantha (Cham.) G. Don, Gen. Hist. 3: 838. 1934. Fig. 2a

Arbusto ereto, 1,5-2 m alt. Tricomas simples nas folhas, raque da inflorescência, brácteas, flores e frutos; tricomas glandulares na face abaxial das folhas. Ramos glabros. Folhas coriáceas, estreito-ovadas, $0,9-1,5 \times 0,4-0,9 \mathrm{~cm}$, glabras a esparsamente cano-pubescentes na nervura principal em ambas as faces, frequentemente híspido-gandular na face abaxial, base cordada, margem revoluta, ligeiramente ondulada, ápice agudo a arredondado, mucronulado; pecíolo 2-4 $\mathrm{mm}$ compr., rígido. Inflorescência racemosa ou paniculada, axilar, 6-12-flora; raque 0,6-1,2 cm compr., densamente cano-tomentosa; brácteas 1-2 mm compr., lanceoladas; bractéolas ca. 0,6 mm compr., triangulares a lineares. Pedicelo 4-7 $\mathrm{mm}$ compr., densamente cano-pubescente; cálice ca. 2,5 $\times 1,5 \mathrm{~mm}$, lobos ovados a triangulares, esparsamente pubescentes, densamente na margem e próximo à base; corola rósea quando em botão, alva após antese, cilíndrica-urceolada, 6-7 mm compr., glabra; filete ca. $4 \mathrm{~mm}$ compr., densamente pubescente, antera ca. 1,5 mm compr.; ovário esparsamente pubescente. Cápsula subglobosa, 5-8 mm diâm., castanho-acinzentada.

Material examinado: Olaria. Serrinha, Sítio do Rinaldo Degredo: 22.VIII.2009, bot., fl. e fr., J.H.C. Ribeiro et al. 193 (CESJ). Rio Preto. Ninho da Égua: 28.IV.2008, fr., F.S. Souza et al. 427 (CESJ); Serra da Caveira D'anta, Fazenda da Tiririca: 23.II.2004, fr., K. Antunes et al. 26 (CESJ, ESA).

Agarista chlorantha é muito similar e normalmente confundida com $A$. hispidula, que também ocorre na Serra Negra, por apresentarem hábito arbustivo, folhas com margem revoluta $\mathrm{e}$ dimensões semelhantes $(0,9-1,5 \times 0,4-0,9 \mathrm{~cm}$ em $A$. chlorantha e 0,6-1,7 ×0,3-0,9 cm em A. hispidula). Porém, $A$. chlorantha diferencia-se pela corola alva e glabra, após a antese. Ocorre nos estados de Minas Gerais, São Paulo até Santa Catarina, e Distrito Federal (BFG 2015). Na Serra Negra A. chlorantha é encontrada em áreas de campo rupestre.
2. Agarista glaberrima (Sleumer) Judd, J. Arnold Arbor. 65: 336. 1984.

Fig. 2b-c

Arbusto ou arvoreta, 0,4-3 m alt. Tricomas simples nas folhas; tricomas glandulares ausentes. Ramos glabros. Folhas coriáceas, frequentemente conduplicadas, ovadas a estreito-ovadas, $2,5-8,4$ $\times 1-3,1 \mathrm{~cm}$, glabras em ambas as faces ou esparsamente cano-pubescentes na nervura principal na face adaxial, frequentemente com glândulas foveoladas conspícuas nigrescentes esparsas na face abaxial, base arredondada a atenuada, por vezes assimétrica, margem plana, inteira, ápice agudo a ligeiramente acuminado, mucronulado, glândula apical alongada; pecíolo 10-30 mm compr., flexível. Inflorescência racemosa ou paniculada, axilar ou terminal, 8-22flora; raque 1,3-8,2 cm compr., glabra; brácteas, ca. $1,5 \mathrm{~mm}$ compr., lineares a triangulares; bractéolas ca. $1 \mathrm{~mm}$ compr., estreito-triangulares. Pedicelo 3-9 mm compr., glabro; cálice 1,8-2 × 1,2-1,3 $\mathrm{mm}$, lobos triangulares, glabros; corola alva a esverdeada com margens e ápice róseos, cilíndricaurceolada, 8-11 mm compr., glabra; filete 3-4 mm compr., densamente pubescente, antera ca. 1,5 mm compr.; ovário glabro. Cápsula subglobosa, 5-8 mm diâm., castanha a negra.

Material examinado: Lima Duarte. 15.XI.2003, fl. e fr., F.R.G. Salimena et al. 1146 (CESJ, ESA); 25.X.2008, fl. e fr., A.C. Mezzonato et al. 4 (CESJ); 25.X.2008, fl. e fr., J.A. Oliveira et al. 5 (CESJ); 25.X.2008, fl. e fr., J.H.C. Ribeiro et al. 24 (CESJ); Fazenda Serra Negra: 4.IV.2009, fr., S.A. Roman et al. 82 (CESJ). Olaria, Serrinha, Sítio do Rinaldo Degredo: 28.VII.2009, fl. e fr., F.S. Souza et al. 740 (CESJ). Rio Preto. 20.VIII.2004, fl. e fr., C.N. Matozinhos et al. 11 (CESJ); 3.II.2009, fl. e fr., J.A. Oliveira et al. 24 (CESJ); Burro de Ouro: 29.IV.2008, fl., S.A. Roman et al. 71 (CESJ); Cânion do Funil: 27.IV.2008, fr., S.A. Roman et al. 60 (CESJ); Próximo a Gruta do Funil: 3.VI.2012, fr., J.H.C. Ribeiro et al. 235 (CESJ); São Lourenço do Funil: 8.XII.2007, fl. e fr., F.R.G. Salimena et al. 2550 (CESJ); Serra da Caveira D'anta, Fazenda da Tiririca: 15.XI.2003, fl. e fr., F.R.G. Salimena et al. 1137 (CESJ, ESA); 15.XI.2003, fl. e fr., F.R.G. Salimena et al. 1146 (CESJ, ESA); 22.II.2004, 


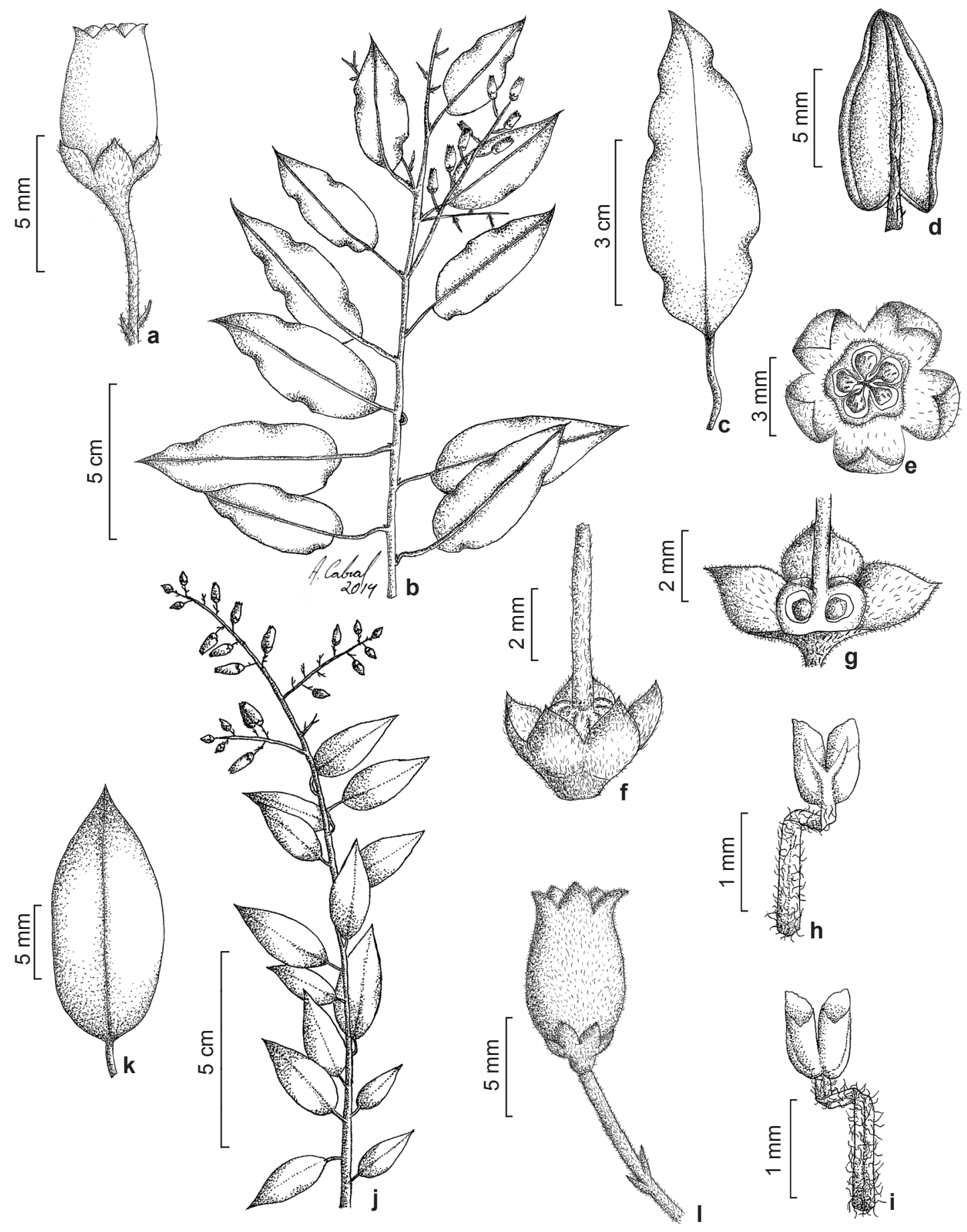

Figura 2 - a. Agarista chlorantha, vista lateral da flor com bractéolas. b-c. Agarista glaberrima - b. detalhe do ramo; c. face adaxial da folha. d-i. Agarista hispidula - d. face abaxial da folha; e. corte tranversal do ovário e sépalas; f. vista lateral do gineceu e sépalas; g. corte longitudinal do ovário e sépalas; h. vista dorsal do estame; i. vista frontal do estame. j-1. Agarista oleifolia - j. detalhe do ramo; k. face adaxial da folha; 1. vista lateral da flor com bractéolas. Figure 2 - a. Agarista chlorantha, lateral view of the flower with bracteoles. b-c. Agarista glaberrima - b. detail of the branch; c. adaxial side of the leaf. d-i. Agarista hispidula - d. abaxial side of the leaf; e. cross section of the ovary and sepals; f. side view of gynoecium and sepals; g. longitudinal section of the ovary and sepals; h. dorsal view of the stamen; i. frontal view of the stamen. $\mathrm{j}-1$. Agarista oleifolia $-\mathrm{j}$. detail of the branch; $\mathrm{k}$. adaxial side of the leaf; 1. lateral view of the flower with bracteoles. 
fr., K. Antunes et al. 4 (CESJ, ESA); 26.II.2004, fl., K. Antunes et al. 61 (CESJ, ESA); Trilha para Água Amarela: 17.III.2007, fl., N.L. Abreu et al. 152 (CESJ); 29.IX.2012, fl. e fr., G.A. Souza et al. 15 (CESJ); Vilarejo do Funil: 21.V.2004, fr., F.R.G. Salimena et al. 1302 (CESJ, ESA); 21.V.2004, fl. e fr., F.R.G. Salimena et al. 1325 (CESJ, ESA).

Agarista glaberrima está relacionada na área de estudo com Agarista oleifolia var. oleifolia como espécie morfologicamente mais próxima, por ambas apresentarem folhas com margem plana, de tamanho semelhante $(2,5-8,4 \times 1-3,1 \mathrm{~cm}$ em A. glaberrima e 2-4,4 × 1,1-2 cm em $A$. oleifolia) e hábito variando de arbusto a arvoreta. Porém A. glaberrima se diferencia desta por apresentar pecíolo flexível de 10-30 mm compr., além de raque da inflorescência e pedicelo glabros. É considerada por alguns autores, como Sleumer (1959), como variedade de $A$. eucalyptoides (Cham. \& Schltdl.) G.Don (a qual não foi registrada na Serra Negra) por ambas apresentarem folhas estreito-alongadas e pendentes, geralmente conduplicadas, com pecíolo flexível e por serem arbustos esguios. Porém, estas espécies se diferenciam quanto ao indumento da raque da inflorescência, que em $A$. eucalyptoides é ferrugíneo-pubescente e em $A$. glaberrima é glabra. Agarista glaberrima é endêmica de Minas Gerais (BFG 2015). Na Serra Negra é encontrada em áreas de campo rupestre e interior de floresta.

\section{Agarista hispidula (DC.) Hook. ex Nied., Bot.} Jahrb. Syst. 11: 236. 1889.

Fig. 2d-i

Arbusto ereto, 0,5-2 $\mathrm{m}$ alt. Tricomas simples nos ramos, folhas, raque da inflorescência, brácteas, flores e frutos; tricomas glandulares ausentes. Ramos esparsa a densamente cano-tomentosos. Folhas coriáceas, ovadas a estreito-ovadas, 0,6-1,7 $\times 0,3-0,9 \mathrm{~cm}$, glabras a glabrescentes na face adaxial, esparsamente cano-pubescentes na nervura principal e próximo à ela, glabras a esparsamente cano-pubescentes em todo o limbo, às vezes com glândulas foveoladas nigrescentes inconspícuas associadas às nervuras secundárias na face abaxial, base cordada, margem revoluta, inteira a ligeiramente ondulada, ápice acuminado a agudomucronulado, glândula apical espesso-alongada; pecíolo 2-3 mm compr., rígido. Inflorescência racemosa ou paniculada, axilar, 4-10-flora; raque 0,9-4 cm compr., densamente cano-pubescente a tomentosa; brácteas ca. 2,5 mm compr., lineares a triangulares; bractéolas 1-2 mm compr., lineares. Pedicelo 4-10 mm compr., densamente canopubescente a tomentoso; cálice 2,5-3,5 × 2-2,5 mm, lobos ovados a deltoides, esparsamente canopubescentes, densamente na margem; corola rósea a avermelhada, cilíndrica-urceolada, 6-10 mm compr., esparsa a densamente cano-pubescente; filete 5,5-6 mm compr., densamente viloso, antera ca. 2 mm compr.; ovário densamente pubescente. Cápsula subglobosa, 4-6 mm diâm., castanhoacinzentada.

Material examinado: Olaria. Serrinha, Sítio do Rinaldo Degredo: 22.VIII.2009, fl. e fr., J.H.C. Ribeiro et al. 198 (CESJ); 22.VIII.2009, bot. e fl., J.A. Oliveira et al. 101 (CESJ). Rio Preto. Burro de Ouro: 29.IV.2008, fl., S.A. Roman et al. 69 (CESJ); 12.VII.2008, fl., N.L. Abreu et al. 248 (CESJ); Cachoeira da Água Vermelha: 26.VI.2008, fl. e fr., F.S. Souza et al. 492 (CESJ); Fazenda Santa Luzia: 31.VI.2007, fl., F.R.G. Salimena et al. 2455 (CESJ); Ninho da Égua: 21.I.2006, fl. e bot., T. Konno et al. 862 (CESJ); São Lourenço do Funil: 8.XII.2007, fl. e fr., F.R.G. Salimena et al. 2548 (CESJ); 8.XII.2007, fl. e fr., L. Menini Neto et al. 446 (CESJ); Trilha atrás da Gruta do Funil: 16.III.2007, fr., N.L. Abreu et al. 139 (CESJ); Trilha para o Ninho da Égua: 22.IV.2005, fl. e bot., $K$. Antunes et al. 173 (CESJ); 31.VII.2009, fl. e fr., J.H.C. Ribeiro et al. 178 (CESJ); Vilarejo do Funil: 21.II.2004, fl. e fr., F.R.G. Salimena et al. 1312 (CESJ, ESA).

Agarista hispidula está relacionada na área de estudo com $A$. chlorantha como espécie morfologicamente mais próxima, da qual é distinta por apresentar corola pubescente e de coloração rósea a avermelhada. Segundo Judd (1995), $A$. hispidula também pode possuir corola alva, fato não observado nos espécimes ocorrentes na Serra Negra. Ocorre em Goiás e principalmente no sul de Minas Gerais, próximo às divisas com São Paulo e Rio de Janeiro (Judd 1995; BFG 2015). Na Serra Negra é encontrada em áreas de campo rupestre e bordas de floresta.

4. Agarista oleifolia (Cham.) G. Don var. oleifolia, Gen. Hist. 3: 838. 1834.

Fig. $2 \mathrm{j}-1$

Arbusto a arvoreta, 2-3 m alt. Tricomas simples nos ramos, folhas, raque da inflorescência, brácteas e frutos; tricomas glandulares ausentes. Ramos esparsamente cano-pubescentes. Folhas coriáceas, elípticas a oblongas, 2-4,4 × 1,1-2 $\mathrm{cm}$, glabras ou esparsamente cano-pubescentes em ambas as faces, às vezes com glândulas foveoladas, nigrescentes, conspícuas no limbo da face abaxial, base arredondada a assimétrica, ligeiramente cordada, margem plana, inteira a ligeiramente ondulada, ápice agudo a acuminado, mucronulado; pecíolo 5-11 mm compr., rígido. Inflorescência racemosa ou paniculada, axilar, 7-12-flora; raque 5,5-9 cm compr., esparsa a 
densamente cano-tomentosa; brácteas $2-3 \mathrm{~mm}$ compr., linear-lanceoladas; bractéolas ca. $2 \mathrm{~mm}$ compr., lineares. Pedicelo 4-8 mm compr., esparsa a densamente cano-tomentoso; cálice 2-2,5 × 1-1,5 mm, lobos triangulares, esparsamente canotomentosos, densamente na margem; corola rósea a avermelhada, cilíndrica a ligeiramente urceolada, 7-8 mm compr., glabra; filete ca. $5 \mathrm{~mm}$ compr., pubescente, antera ca. 1,5 mm compr.; ovário densamente pubescente. Cápsula subglobosa, 4-6 mm diâm., negra.

Material examinado: Rio Preto. Fazenda da Tiririca: 23.II.2004, fl., F.R.G. Salimena et al. 1236 (CESJ, ESA); São Lourenço do Funil: 7.XII.2007, fl. e fr., F.R.G. Salimena et al. 2549 (CESJ).

Agarista oleifolia var. oleifolia está relacionada na área de estudo com $A$. glaberrima como espécie morfologicamente mais próxima (detalhes no comentário desta espécie). Porém A. oleifolia se diferencia desta, pela presença de pilosidade nos ramos, raque da inflorescência e pedicelo, além de pecíolo rígido. Judd (1984) reconheceu dois táxons baseado no indumento da raque da inflorescência, $A$. oleifolia var. oleifolia e A. oleifolia var. glabra (Meisn.) Judd, dos quais apenas o primeiro ocorre na área de estudo. A variedade oleifolia possui a raque da inflorescência esparsa a densamente pubescente ( $v s$. raque da inflorescência glabra na variedade glabra). Agarista oleifolia está amplamente distribuída no Brasil, ocorrendo desde a Bahia até o Paraná, estendendo-se para oeste, no estado do Mato Grosso (BFG 2015). Na Serra Negra é encontrada em áreas de campo rupestre.

5. Gaultheria eriophylla (Pers.) Sleumer ex Burtt var. eriophylla, Bot. Mag., 170: t. 254. 1955.

Fig. 3a-i

Subarbusto, arbusto ou arvoreta, 0,6-2 m alt. Tricomas simples não glandulares nos ramos, folhas, raque da inflorescência, brácteas, flores e frutos; tricomas glandulares ausentes. Ramos densamente cano-tomentosos a lanosos. Folhas alternas, coriáceas, ovadas, oblongas ou largoelípticas, 2,2-9,1 × 1,5-6,2 cm, esparsamente ferrugíneas a cano-pubescentes, densamente na nervura principal na face adaxial, esparsa a densamente ferrugíneo-tomentosa a lanosa, densamente nas nervuras na face abaxial, base arredondada ou ligeiramente cordada, margem revoluta, ligeiramente serrilhada, ápice agudo a obtuso, mucronulado proeminente; pecíolo ca. $5 \mathrm{~mm}$ compr., rígido. Inflorescência racemosa, axilar, 7-20-flora; raque $3-12 \mathrm{~cm}$ compr., densamente ferrugíneo-tomentosa a lanosa; bráctea floral 1, 6-10 mm compr., linear-acuminada; bractéolas 2 , ca. $3,5 \mathrm{~mm}$ compr., lanceoladas. Pedicelo 5-8 mm compr., hirsuto; cálice $2-2,7 \times 1,5-2 \mathrm{~mm}$, lobos ovados, densamente ferrugíneo-tomentosos a lanosos; corola rósea ou alva com máculas róseas, urceolada, 6-7 mm compr., densamente ferrugíneo-tomentosa a lanosa; filete ca. $2 \mathrm{~mm}$ compr., pubescente, antera ca. 1,5 mm compr.; ovário súpero, 5-locular, lóculo multiovulado, densamente pubescente. Cápsula subglobosa, 4-6 mm diâm., vinácea, conspicuamente circundada por cálice carnoso e aderente.

Material examinado: Olaria. Serrinha, Sítio do Rinaldo Degredo: 28.VII.2009, fl., F.S. Souza et al. 745 (CESJ). Rio Preto. Burro de Ouro: 26.II.2006, fl., P.L. Viana et al. 1978 (CESJ); 12.VII.2008, fl., N.L. Abreu et al. 246 (CESJ); Ninho da Égua: 28.IV.2008, fl. e fr., S.A. Roman et al. 65 (CESJ); Serra da Caveira D'anta, Fazenda da Tiririca: 23.II.2004, fl., K. Antunes et al. 23 (CESJ); Trilha para Cachoeira do Marciano: 30.VIII.2008, fl., N.L. Abreu et al. 277 (CESJ); 4.II.2009, fl., J.A. Oliveira et al. 29 (CESJ); Trilha para o Ninho da Égua: 26.VIII.2004, fr., C.N. Matozinhos et al. 45 (CESJ); 29.IV.2008, fl. e fr., S.A. Roman et al. 67 (CESJ); 31.VII.2009, fl. e fr., J.H.C. Ribeiro et al. 180 (CESJ); 16.VII.2014, fr., L.L. Justino et al. 69 (CESJ).

Gaultheria é constituído por 115 espécies de distribuição cosmopolita (Kinoshita \& Romão 2012). No Brasil, foram relacionadas oito espécies e um híbrido (BFG 2015).

Gaultheria eriophylla var. eriophylla é a única das duas variedades da espécie ocorrente no Brasil (BFG 2015), sendo G. eriophylla var. mucronata (J.Rémy) Luteyn restrita ao Peru e Bolívia (Stevens 1971). Pode ser facilmente reconhecida por apresentar indumento densamente ferrugíneo-tomentoso na face abaxial das folhas e na raque da inflorescência (Kinoshita \& Romão 2012). É endêmica da Região Sudeste do Brasil (BFG 2015). Na Serra Negra é encontrada em áreas de campo rupestre.

\section{Gaylussacia Kunth}

Subarbustos, arbustos ou arvoretas, eretos ou procumbentes; ramos glabrescentes a pilosos. Folhas alternas, adensadas a esparsas, cartáceas a subcoriáceas, margem ligeiramente revoluta, inteira a ligeiramente serreada, glabras ou pilosas, com tricomas simples ou glandulares, frequentemente com glândulas capitadas ou clavadas, ápice com glândula espessa. Inflorescência tipo racemo, 


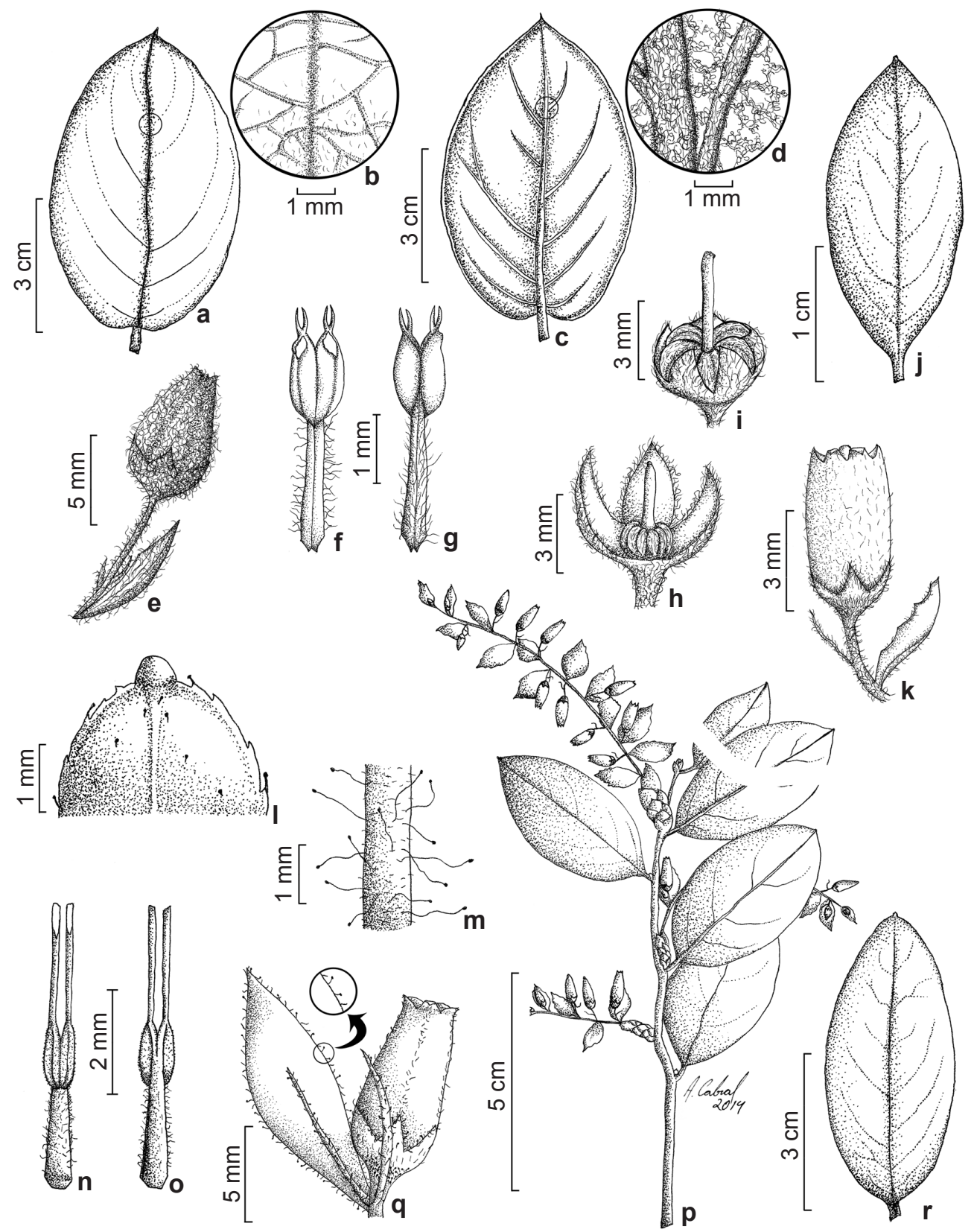

Figura 3 - a-i. Gaultheria eriophylla - a. face adaxial da folha; b. detalhe da nervura principal; c. face abaxial da folha; d. detalhe da nervura principal; e. vista lateral da flor com bractéolas e bráctea; f. vista frontal do estame; g. vista dorsal do estame; h. vista lateral do gineceu e sépalas; i. fruto imaturo com estilete persistente e sépalas. j-k. Gaylussacia densa - j. face adaxial da folha; k. vista lateral da flor com bractéola e bráctea. 1-o. Gaylussacia montana - 1. detalhe da glândula apical da folha; $m$. detalhe do pedicelo; n. vista frontal do estame; o. vista dorsal do estame. p-r. Gaylussacia rhododendron - p. detalhe do ramo; q. vista lateral da flor com bractéolas e bráctea e detalhe do indumento da bráctea; r. face adaxial da folha.

Figure 3 - a-i. Gaultheria eriophylla - a. adaxial side of the leaf; b. detail of the main vein; c. abaxial side of the leaf; d. detail of the main vein; e. lateral view of the flower with bracteoles and bract; f. frontal view of the stamen; g. dorsal view of the stamen; h. lateral view of gynoecium and sepals; i. immature fruit with persistent style and sepals. j-k. Gaylussacia densa - j. adaxial side of the leaf; k. lateral view of the flower with bracteole and bract. 1-o. Gaylussacia montana-1. detail of the apical gland in the leaf; $\mathrm{m}$. detail of the pedicel; n. frontal view of the stamen; o. dorsal view of the stamen. p-r. Gaylussacia rhododendron - p. detail of the branch; q. lateral view with bracteoles and bracts and detail of the indumenta of bract; $r$. adaxial side of the leaf. 
axilar a terminal, bracteada na base da raque, pilosa, geralmente com glândulas; bráctea floral 1, vistosa, às vezes foliácea; bractéolas 2. Flores pentâmeras actinomorfas, pendentes; cálice 5-lobado, persistente; corola gamopétala, pentâmera, campanulada, tubuloso-campanulada, cilíndrico-urceolada ou urceolada, alva a rósea; estames 10, iguais entre si; filete reto, achatado, dorso piloso, anteras longo-tubulosas, bífidas, dorsifixas, deiscência poricida ou por pequena fenda apical introrsa; ovário ínfero, pseudo 10-locular, lóculo uniovulado, estilete delgado. Nuculânio, subgloboso; 10 pirênios, sementes lenticulares.

Gaylussacia abrange 54 espécies, com padrão de distribuição geográfica disjunto, ocorrendo no leste da América do Norte e na América do Sul, não possuindo representantes na América Central (Kinoshita-Gouvêa 1980; Romão 2011). No Brasil, ocorrem 43 espécies (BFG 2015).

\section{Chave para identificação das espécies de Gaylussacia}

1. Tricomas glandulares ausentes; folhas com margem inteira; corola esparsamente cano- pubescente, ca. $5 \mathrm{~mm}$ compr. 6. G. densa var. densa

1'. Tricomas glandulares presentes; folhas com margem ligeiramente serrilhada a serreada; corola glabra, 6-9 mm compr.

2. Folhas 2-5,8 $\times$ 0,8-3 cm; pedicelo 4-5 mm compr.; brácteas 7-22 $\mathrm{mm}$ compr.; bractéolas lanceoladas; corola cilíndrico-urceolada; nuculânio 4-6 mm diâm. 8. G. rhododendron

2'. Folhas 1,3-2,3 $\times 0,4-0,8 \mathrm{~cm}$; pedicelo ca. $2 \mathrm{~mm}$ compr.; brácteas 4-7 mm compr.; bractéolas lineares; corola campanulada a tubuloso-campanulada; nuculânio ca. $3 \mathrm{~mm}$ diâm.

7. G. montana var. angustifolia

6. Gaylussacia densa Cham. var. densa, Linnaea 8: 496.1833.

Fig. $3 \mathrm{j}-\mathrm{k}$

Arbusto, ca. $1 \mathrm{~m}$ alt. Tricomas simples nos ramos, folhas, raque da inflorescência, brácteas, flores e frutos; tricomas glandulares ausentes. Ramos glabrescentes. Folhas subcoriáceas, elípticas a ligeiramente ovadas, $1,5-2,9 \times 0,6-1,3 \mathrm{~cm}$, esparsamente cano-pubescentes, densamente na nervura principal em ambas as faces, frequentemente com glândulas capitadas ou clavadas, rubronigrescentes, esparsas na face abaxial, base aguda a obtusa, margem ligeiramente revoluta próximo à base, inteira, ápice obtuso a arredondado, glândula apical espesso-calosa; pecíolo ca. $3 \mathrm{~mm}$ compr., rígido. Inflorescência racemosa, axilar ou terminal, 6-10-flora; raque 1-2,8 cm compr., esparsamente cano-pubescente com glândulas ferrugíneas clavados ou capitados; brácteas 5-8 $\mathrm{mm}$ compr., rômbicas, com ápice avermelhado; bractéolas ca. $3 \mathrm{~mm}$ compr., lineares a lanceoladas. Pedicelo 2-3 mm compr., pubescente; cálice ca. 1,5 × 1,5 $\mathrm{mm}$, lobos deltoides, esparsa a densamente canopubescentes, margem densamente cano-pubescente, glândulas ferrugíneas clavadas adensadas próximo ao hipanto; corola alva passando a rósea, urceolada, ca. $5 \mathrm{~mm}$ compr., esparsamente cano-pubescente; filete ca. $2 \mathrm{~mm}$ compr., pubescente, antera ca. 2 mm compr.; hipanto glabro a setoso. Nuculânio subgloboso, 4-5 mm diâm., esverdeado a arroxeado.
Material examinado: Rio Preto. Cachoeira da Água Vermelha: 26.VI.2008, fl. e fr., F.S. Souza et al. 491 (CESJ); Ninho da Égua: 28.IV.2008, fr., S.A. Roman et al. 64 (CESJ, ESA); Sítio do Neném Roque: 27.III.2013, fl. e fr., K. Antunes et al. 425 (CESJ); Trilha para o Marciano: 22.IV.2004, fr., N.L. Abreu et al. 17 (CESJ, ESA); 4.II.2009, fl., J.A. Oliveira et al. 28 (CESJ); Trilha para o Ninho da Égua: 21.I.2006, fl., T. Mota et al. 6 (CESJ); 16.VII.2014, fl., L.L. Justino et al. 84 (CESJ).

Gaylussacia densa var. densa é um táxon muito variável principalmente em relação ao indumento dos ramos e das folhas, que podem ser glabras até densamente vilosas (Romão 2011). Nos espécimes encontrados na Serra Negra há um padrão relacionado ao indumento dos ramos (glabrescentes) e folhas (esparsamente canopubescente, densamente na nervura principal em ambas as faces). Gaylussacia densa var. densa está relacionada morfologicamente na área de estudo com G. montana (Pohl) Sleumer var. angustifolia, por apresentarem hábito arbustivo, atingindo 1 $\mathrm{m}$ alt. e folhas com dimensões similares $(1,5-2,9$ $\times 0,6-1,3 \mathrm{~cm}$ em $G$. densa var. densa e 1,3-2,3 $\times 0,4-0,8 \mathrm{~cm}$ em $G$. montana var. angustifolia). No entanto, distingue-se de G. montana var. angustifolia por apresentar corola esparsamente cano-pubescente e tricomas glandulares ausentes na planta. Gaylussacia densa var. densa é encontrada na Bahia e estados da Região Sudeste, ocorrendo no Domínio do Cerrado ao longo da Cadeia do 
Espinhaço e Domínio Atlântico nas regiões de maiores altitudes da Serra da Mantiqueira (Romão 2011; BFG 2015). Na Serra Negra pode ser encontrada em áreas de campo rupestre.

7. Gaylussacia montana var. angustifolia (Meisn.) Sleumer, Bot. Jahrb. Syst. 86: 344. 1967.

Fig. 31-o

Arbusto, 0,7-1 m alt. Tricomas simples e glandulares nos ramos, folhas, raque da inflorescência, brácteas, flores e frutos. Ramos glabrescentes. Folhas subcoriáceas, estreitoelípticas a oblanceoladas, $1,3-2,3 \times 0,4-0,8$ $\mathrm{cm}$, glabras a esparsamente cano-pubescentes, densamente na nervura principal, frequentemente esparsamente híspido-glandular e com glândulas clavadas ou capitadas rubro-nigrescentes esparsas na face adaxial, esparsamente pubescentes na nervura principal, em geral esparsamente híspido-glandular e com glândulas adensadas na face abaxial, base aguda a obtusa, margem ligeiramente revoluta, ligeiramente serrilhada em direção ao ápice, comumente com tricomas glandulares nos dentes, ápice agudo a arredondado, glândula apical espessa; pecíolo $2-3 \mathrm{~mm}$ compr., rígido. Inflorescência racemosa, axilar ou subterminal, 8-12-flora; raque 2,5-3 cm compr., esparsamente cano-pubescente, mais densamente viloso-glandular, com glândulas capitadas ou clavadas rubro-amareladas dispostas esparsamente; brácteas 4-7 mm compr., elípticas a oblanceoladas, avermelhadas; bractéolas 2-3,5 mm compr., lineares. Pedicelo ca. 2 $\mathrm{mm}$ compr., esparsamente cano-pubescente e viloso-glandular, frequentemente com glândulas clavadas ou pediceladas rubro-amareladas, dispostas esparsamente; cálice ca. $2 \times 1,5 \mathrm{~mm}$, lobos deltoides, esparsamente cano-pubescentes, margem densamente viloso-glandular; corola alva a rósea, campanulada a tubuloso-campanulada, 6-8 mm compr., glabra; filete ca. 2,5 mm compr., esparsamente pubescente, antera ca. 4 $\mathrm{mm}$ compr.; hipanto esparsamente pubescente e esparsa a densamente viloso-glandular. Nuculânio subgloboso, ca. $3 \mathrm{~mm}$ diâm., verde quando imaturo. Material examinado: Lima Duarte. Trilha para o Marciano: 14.X.2008, fl., N.L. Abreu et al. 282 (CESJ). Rio Preto. Acima da Gruta do Funil: 13.XI.2004, fl., C.N. Matozinhos et al. 158 (CESJ, ESA); São Lourenço do Funil: 9.XII.2007, fr., S.A. Roman et al. 40 (CESJ); Sítio do Neném Roque, Trilha para a Antena: 23.XI.2014., fl. e fr., L.L. Justino et al. 123 (CESJ, ESA); Vilarejo do Funil: 21.V.2004, fl., F.R.G. Salimena et al. 1350 (CESJ, ESA).
Gaylussacia montana var. angustifolia, na área de estudo, compartilha afinidades com $G$. densa var. densa (detalhes no comentário desta variedade). Romão (2011) diferencia $G$. montana var. angustifolia das outras duas variedades existentes pela forma e indumento das folhas, além do indumento da corola. Gaylussacia montana (Pohl) Sleumer var. montana e G. montana var. organensis Sleumer são caracterizadas pelo seguinte conjunto de caracteres: folhas com limbo elíptico a obovado, suborbicular ou ovado, face superior pubescente e frequentemente híspidoglandular e corola tomentosa ou pubescente e híspido-glandular nos ângulos. Em contrapartida G. montana var. angustifolia apresenta folhas com limbo estreito-elíptico a oblanceolado e face adaxial glabra, além de corola glabra (Romão 2011). No presente trabalho, os limites da distribuição geográfica deste táxon foram ampliados para o Complexo da Mantiqueira, pois era até então considerado endêmico da porção Sul da Cadeia do Espinhaço (Romão 2011). Na área de estudo, os espécimes são encontrados em interior de floresta e, predominantemente, nos campos rupestres em populações que dominam amplos trechos da paisagem local.

8. Gaylussacia rhododendron Cham. \& Schltdl., Linnaea 1: 533. 1826.

Fig. 3p-r

Subarbusto, arbusto ou arvoreta, 0,3-2 m alt. Tricomas simples nos ramos, folhas, raque da inflorescência, brácteas, flores e frutos; tricomas glandulares na raque da inflorescência, brácteas, cálice, frutos e comumente na face abaxial das folhas. Ramos glabros a esparsamente cano-vilosos. Folhas cartáceas a subcoriáceas, estreito a largo-elípticas ou ligeiramente ovadas, $2-5,8 \times 0,8-3 \mathrm{~cm}$, esparsa a densamente canopubescentes na nervura principal em ambas as faces, com glândulas clavadas rubro-nigrescentes esparsas dispostas por todo o limbo mais densamente na face abaxial, base aguda a obtusa, margem ligeiramente revoluta, ligeiramente serreada, ápice obtuso a arredondado, glândula apical espesso-alongada; pecíolo ca. $2-5 \mathrm{~mm}$ compr., rígido. Inflorescência racemosa, axilar, 6-12-flora; raque 2,7-8,8(-13) cm compr., densamente cano-pubescente e esparsamente viloso-glandular; brácteas 7-22 mm compr., elípticas a rômbicas, foliáceas; bractéolas $2-5 \mathrm{~mm}$ compr., lanceoladas. Pedicelo 4-5 mm compr., densamente cano-pubescente e esparsamente viloso-glandular; cálice $1,6-2 \times 1,5 \mathrm{~mm}$, lobos 
triangulares, esparsamente cano-pubescentes, esparsa a densamente híspido-glandular próximo ao hipanto e na margem dos lobos; corola alva a rósea, cilíndrico-urceolada, 6-9 $\mathrm{mm}$ compr., glabra; filete ca. 1,8 mm compr., pubescente, antera ca. 2,5 mm compr.; hipanto esparsamente cano-pubscente e esparsa a densamente híspidoglandular. Nuculânio sub-globoso, 4-6 mm diâm., verde quando imaturo.

Material examinado: Olaria. Serrinha, Poços: 28.VII.2009, fl., F.S. Souza et al. 737 (CESJ). Rio Preto. Burro de Ouro: 20.V.2006, fr., P.L. Viana et al. 2042 (CESJ, ESA); Fazenda Tiririca: 23.II.2004, fr., F.R.G. Salimena et al. 1252 (CESJ, ESA); 13.XI.2004, fr., C.N. Matozinhos et al. 136 (CESJ, ESA); Ninho da Égua: 23.VIII.2007, fl. e fr., F.S. Souza et al. 265 (CESJ); 14.X.2007, fl. e fr., S.A. Roman et al. 34 (CESJ); 28.IV.2008, fl. e fr., S.A. Roman et al. 66 (CESJ); São Lourenço do Funil: 9.XII.2007, fl. e fr., S.A. Roman et al. 41 (CESJ); Sítio do Neném Roque: 23.XI.2014, fl., L.L. Justino et al. 117 (CESJ, ESA); Trilha para o Burro de Ouro: 12.VII.2008, fl., N.L. Abreu et al. 249 (CESJ); Trilha para o Ninho da Égua: 21.VIII.2004, fl. e fr., C.N. Matozinhos et al. 46 (CESJ); 31.VII.2009, fl., J.H.C. Ribeiro et al. 179 (CESJ); 20.X.2012, fl., K. Antunes et al. 343 (CESJ); 16.VII.2014, fl. e fr., L.L. Justino et al. 70 (CESJ).

Gaylussacia rhododendron assemelha-se a G. brasiliensis (Spreng.) Meisn. var. brasiliensis no aspecto geral da planta (Kinoshita-Gouvêa 1980), ambas variando de arbustos a arvoretas, pecíolo até ca. $5 \mathrm{~mm}$ compr., rígido, brácteas foliáceas e corola cilíndrica a urceolada. No entanto, G. rhododendron diferencia-se por apresentar tricomas glandulares, enquanto $G$. brasiliensis var. brasiliensis apresenta somente tricomas simples ou ramos glabros (Romão 2011). Gaylussacia rhododendron é endêmica da Região Sudeste, distribuindo-se no Domínio Atlântico, principalmente ao longo da Serra do Mar em São Paulo, ocorrendo eventualmente na Serra da Mantiqueira em Minas Gerais e Rio de Janeiro (Romão 2011; BFG 2015). Na área de estudo, os espécimes foram encontrados em campos rupestres, bordas de floresta e próximo de cursos d'água.

\section{Agradecimentos}

À FAPEMIG, a concessão de auxílio ao projeto "Estudos Florísticos na Serra Negra, Minas Gerais" (CRA 1891/06 e CRA 18105.02/07); à Dra. Fátima Salimena, coordenadora do projeto e curadora do herbário CESJ, onde o estudo foi conduzido; aos revisores e editor pelas contribuições ao manuscrito.

\section{Referências}

BFG. 2015. Growing knowledge: an overview of Seed Plant diversity in Brazil. Rodriguésia 66: 1085-1113.

Fidalgo, O. \& Bononi, V.L. 1984. Técnicas de coleta, preservação e herborização de material botânico (Manual n. 4). Instituto de Botânica, São Paulo. 62p.

Gonçalves, E.G. \& Lorenzi, H. 2007. Morfologia vegetal: organografia e dicionário ilustrado de morfologia das plantas vasculares. Instituto Plantarum, Nova Odessa, 416p.

Harris, J.G. \& Harris, M.W. 2003. Plant identification terminology: an illustrated glossary. $2^{\mathrm{a}}$ ed. Spring Lake Publ., Spring Lake. 216p.

Judd, W.S. 1984. A taxonomic revision of the American species of Agarista (Ericaceae). J. Arnold Arb. 65: 255-342.

Judd, W.S. 1995. Agarista G. Don. In: Luteyn, J.L.; Judd, W.S.; Clemants, S.E.; Diggs, G.M.; Sørensen, P.D.; Dorr, J.L. \& Wallace, G.D. (eds.). Ericaceae - part II. The superior ovaried genera. Flora Neotropica Monograph 66: 295-344.

Judd, W.S.; Campbell, C.S.; Kellogg, E.A.; Stevens, P.F. \& Donoghue, M.J. 2008. Plant systematics, a phylogenetic approach. $3^{\mathrm{a}}$ ed.. Sinauer Associates Inc., Sunderland. 612p.

Kinoshita-Gouvêa, L.S. 1980. Estudos taxonômicos e fitogeográficos da família Ericaceae no Brasil. Tese de Doutorado. Universidade de São Paulo, São Paulo. 319p.

Kinoshita, L.S. \& Romão, G.O. 2011. Ericaceae. In: Cavalcanti, T.B. \& Silva, A.P. (eds.). Flora do Distrito Federal, Brasil. Vol. 9. Embrapa Recursos Genéticos e Biotecnologia, Brasília. Pp.115-127.

Kinoshita, L.S. \& Romão, G.O. 2012. Flora Fanerogâmica do Estado de São Paulo: Ericaceae. In: Wanderley, M.G.L.; Shepherd, G.J.; Melhem, T.S.; Giulietti, A.M. \& Martins, S.E. (orgs.). Flora Fanerogâmica do Estado de São Paulo. Instituto de Botânica, São Paulo. Vol. 7, pp. 151-172.

Marinero, F.E.C.; Maranho, L.T. \& Hatschbach, G.G. 2007. O gênero Gaultheria L. (Ericaceae) no Estado do Paraná, Brasil. Revista Brasileira de Biociências 5: 615-617.

Menini Neto, L.; Matozinhos, C.N.; Abreu, N.L; Valente, A.S.M.; Souza, F.S.; Viana, P.L. \& Salimena, F.R.G. 2009. Flora vascular não-arbórea de uma floresta de grota na Serra da Mantiqueira, Zona da Mata de Minas Gerais, Brasil. Biota Neotropica 9: 1-13.

Mezabarba, V.; Vianna Filho, M.D.M.; Borges, R.A.X. \& Mansano, V.F. 2013. Ericaceae do Parque Nacional do Itatiaia, RJ, Brasil. Hoehnea 40: 115-130.

Myers, N.; Mittermeyer, R.A.; Fonseca, G.A.B. \& Kent, J. 2000. Biodiversity hotspots for conservation priorities. Nature 403: 853-858.

Radford, A.E. 1974. Fundamental of plant systematics. Harper \& Row, New York. 507p. 
Romão, G.O. \& Souza, V.C. 2003. Flora fanerogâmica do Parque Nacional do Caparaó: Ericaceae. Pabstia 14: $1-12$.

Romão, G.O.; Wanderley, M.G.L. \& Yokoya, N. 2004. Flora de Grão-Mogol, Minas Gerais: Ericaceae. Boletim de Botânica da Universidade de São Paulo 22: 97-100.

Romão, G.O. 2011. Revisão taxonômica de Gaylussacia Kunth (Ericaceae) e estudos da filogenia do gênero. Tese de Doutorado. Universidade Estadual de Campinas, Campinas. 494p.

Salimena, F.R.G.; Matozinhos, C.N.; Abreu, N.L.; Ribeiro, J.H.C.; Souza, F.S. \& Menini Neto, L. 2013. Flora fanerogâmica da Serra Negra, Minas Gerais, Brasil. Rodriguésia 64: 311-320.

Silva, R.R. \& Cervi, A.C. 2006. As Ericaceae Juss. nativas no Estado do Paraná, Brasil. Acta Biologica Paranaense 35: 1-45.

Sleumer, H. 1959. Studien über die Gattung Leucothoe D. Don. Botanische Jahrbücher fur Systematik,
Pflanzengeschichte und Pflanzengeographie 78: 435-480.

Souza, V.C. \& Lorenzi, H. 2012. Botânica Sistemática: guia ilustrado para identificação das famílias de Fanerógamas nativas e exóticas do Brasil, baseado em APG III. $3^{\text {a }}$ ed. Instituto Plantarum, Nova Odessa. 768p.

Stevens, P.F. 1971. A classification of the Ericaceae: sub-families and tribes. Botanical Journal of the Linnean Society 64: 1-53.

Thiers, B. 2015. [continuously updated]. Index Herbariorum: A global directory of public herbaria and associated staff. New York Botanical Garden's Virtual Herbarium. Disponível em $(<\mathrm{http}: / /$ sweetgum.nybg.org/ih/>). Acesso em 27 maio 2015.

Valente, A.S.M.; Garcia, P.O.; Salimena, F.R.G. \& Oliveira-Filho, A.T. 2011. Composição, estrutura e similaridade florística da Floresta Atlântica, na Serra Negra, Rio Preto - MG. Rodriguésia 62: 321-340. 